\title{
P-99: Effects of Width of Address Electrode on Sustain and Address Discharge Characteristics in AC Plasma Display Panel
}

\author{
Jae Young Kim, Soo Kwan Jang, Heung-Sik Tae, Eun Young Jeong*, \\ Soon Bae Kim*, Bong Kyuong, Park*, Kwang Jong Suh*, Jeong Chull Ahn*, \\ Eun Gi Heo*, Byung Hak Lee* and Kwang Sik Lee*
}

\author{
School of Electronic and Electrical Engineering, Kyungpook National University, \\ 1370 Sankyuk-Dong, Buk-Gu, Daegu, 702-701, Korea \\ *PDP Development Team, PDP Division, Samsung SDI Co. Ltd., \\ Cheonan, Chungnam, 330-300,Korea
}

\begin{abstract}
The width of an address electrode is an important parameter to affect both the address and sustain discharge characteristics in $A C-P D P$. It is found numerically that as the width of an address electrode is wider, the capacitance between the sustain and address electrodes $\left(C_{A Y}\right)$ increases but the capacitance between the two sustain electrodes $\left(C_{X Y}\right)$ decreases. The resultant changes in the sustain and address discharge characteristics, such as a firing voltage, sustain voltage, discharge delay time and full-white luminance were examined in the 50-in. ac-PDP with a high Xe (>10\%) content. The increase in the address electrode width causes an increase in the firing and sustain voltage between the sustain electrodes, which are due to the decrease in the capacitance between two sustain electrodes and the increase in the wall charges accumulation toward the address electrode. In particular, the full-white luminance increases with an increase in the address electrode width. As the address electrode width becomes broaden, the sustain discharge path is lengthened toward the address electrode and the discharge volume is also enlarged. Therefore, the amount of the IR, VUV and Ne rays can be emitted considerably.
\end{abstract}

\section{Introduction}

It is well-known that if the width of an address electrode is wider, the faster and more stable discharge can be produced during an address period [1], which can be explained by the change in the capacitance of the rear panel due to the variation in width of an address electrode. However, it is also found that the change in the address electrode width can affect both the capacitance not only between the sustain and address electrodes but also between two

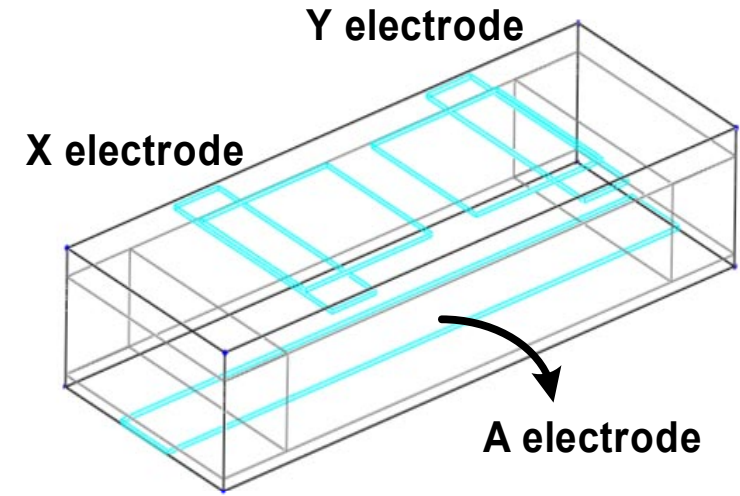

Fig. 1. Schematic diagram of the cell structure used in a calculation of the capacitance

\begin{tabular}{|c|c|c|}
\hline & Parameter & Specification \\
\hline Cell & Cell pitch & $810 \times 175 \mu \mathrm{m}$ \\
\hline $\begin{array}{c}\text { Sustain } \\
\text { electrode }\end{array}$ & Width / gap & $200 \mu \mathrm{m} / 70 \mu \mathrm{m}$ \\
\hline $\begin{array}{l}\text { Address } \\
\text { electrode }\end{array}$ & Width & $60,90,100,120,150 \mu \mathrm{m}$ \\
\hline \multirow{3}{*}{ Barrier rib } & Height & $120 \mu m$ \\
\hline & Upper / lower width & $25 \mu \mathrm{m} / 50 \mu \mathrm{m}$ \\
\hline & Permittivity & 20 \\
\hline \multirow{2}{*}{$\begin{array}{c}\text { Front } \\
\text { dielectric layer }\end{array}$} & Thickness & $35 \mu m$ \\
\hline & Permittivity & 13 \\
\hline \multirow{2}{*}{$\begin{array}{c}\text { Rear } \\
\text { dielectric layer }\end{array}$} & Thickness & $15 \mu m$ \\
\hline & Permittivity & 20 \\
\hline \multirow{2}{*}{ Phosphor } & Lateral thickness & $30 \mu m$ \\
\hline & Lower thickness & $10 \mu m$ \\
\hline
\end{tabular}

Table 1. Geometrical parameters for a calculation of the capacitance 
sustain electrodes [2], which implies that the change in the address electrode width can affect both the address and sustain discharge characteristics of an AC-PDP. This phenomenon has a significant importance in view of the driving of the PDP panel. This provides a possibility of control over the sustain discharge and plate gap discharge independently. In this paper, the cell capacitance variation is calculated as a function of the address electrode width. The resultant changes in the sustain and address discharge characteristics, such as a firing voltage, sustain voltage, discharge delay time and full white luminance were examined in the 50-in. ac-PDP with a high Xe (>10\%) content.

\section{Calculation of capacitances - Simulations}

For calculating the cell capacitance, the numerical method is carried out with using Trefftz method in ANSYS simulation code. The cell capacitance is calculated by equation (1).

$$
\begin{aligned}
C & =\frac{Q}{V}(C / V \text { or } F) \\
Q & =\int_{S} \rho_{S} d s=\int_{S} \varepsilon \hat{\boldsymbol{n}} \cdot \boldsymbol{E} d s=\int_{S} \varepsilon \boldsymbol{E} \cdot d \boldsymbol{s} \\
V & =V_{12}=-\int_{P_{2}}^{P_{1}} \boldsymbol{E} \cdot d \boldsymbol{l} \\
\therefore \quad & C=\frac{Q}{V}=\frac{\int_{S} \varepsilon \boldsymbol{E} \cdot d \boldsymbol{s}}{-\int_{l} \boldsymbol{E} \cdot d \boldsymbol{l}}(F) \quad \ldots \ldots
\end{aligned}
$$

The schematic diagram of cell structure used in our simulation is indicated in Fig. 1, and the geometrical parameters are listed in Table 1. The widths of an address electrode are varied: 60, 90, 100, 120, and $150 \mu \mathrm{m}$, respectively. Fig. 2 and Table 2 show the resultant capacitances between two sustain electrodes $\left(\mathrm{C}_{\mathrm{XY}}\right)$ and between the sustain and address electrodes $\left(\mathrm{C}_{\mathrm{AY}}\right)$ per unit cell with respect to the width of an address electrode. The $\mathrm{C}_{\mathrm{XY}}$ per unit cell decreases linearly from 0.0146 to $0.0135[\mathrm{pF}]\left(\Delta \mathrm{C}_{\mathrm{XY}}=0.0011 \mathrm{pF}\right)$ and the $\mathrm{C}_{\mathrm{AY}}$ per unit cell increases from 0.0200 to $0.0244[\mathrm{pF}]$ $\left(\Delta \mathrm{C}_{\mathrm{AY}}=0.0044 \mathrm{pF}\right)$ and with an increase in the address electrode width. The change in the address electrode width induces the change of the capacitance, $\mathrm{C}_{\mathrm{AY}}$, which is related to the address discharge about four times as large as the change of the capacitance, $\mathrm{C}_{\mathrm{XY}}$, which is related to the sustain discharge.

\section{Discharge characteristics - Experiments}

To investigate the effects of the cell capacitance caused by the address electrode width on both the address and sustain discharges, the experimental measurements are carried out on the 50 -in. PDP panel with four blocks divided by the address electrode width ranging from 60 to $150 \mu \mathrm{m}$ at the intervals of $30 \mu \mathrm{m}$. Fig. 3

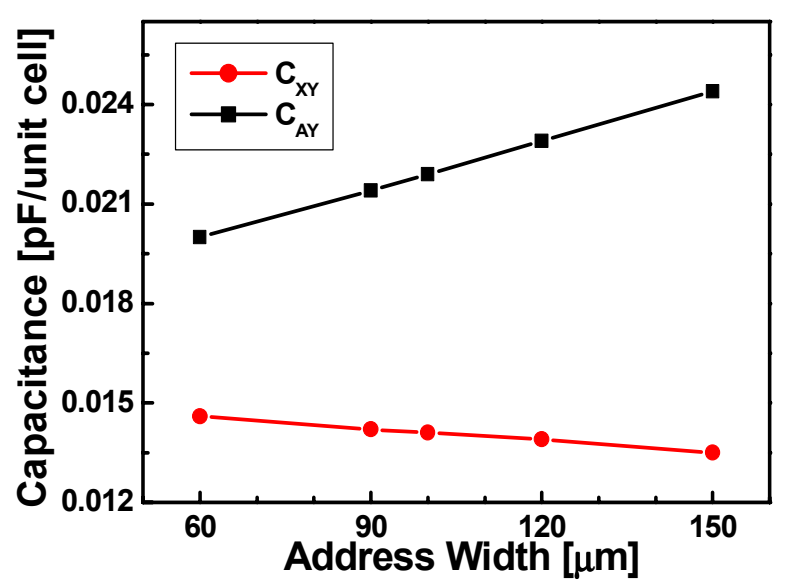

Fig. 2. Capacitances between two sustain electrodes $\left(C_{X Y}\right)$ and between the sustain and address electrodes $\left(C_{A Y}\right)$ per unit cell

\begin{tabular}{|c|c|c|c|c|c|r|}
\hline & \multicolumn{6}{|c|}{ Add_width } \\
\cline { 2 - 6 } & $60_{\text {um }}$ & $90_{\text {um }}$ & $100_{\text {um }}$ & $120_{\text {um }}$ & $150_{\text {um }}$ & unit: [pF] \\
\hline X-Y & $4.37 \mathrm{E}-02$ & $4.27 \mathrm{E}-02$ & $4.24 \mathrm{E}-02$ & $4.17 \mathrm{E}-02$ & $4.06 \mathrm{E}-02$ & $3-$-cell \\
& $1.46 \mathrm{E}-02$ & $1.42 \mathrm{E}-02$ & $1.41 \mathrm{E}-02$ & $1.39 \mathrm{E}-02$ & $1.35 \mathrm{E}-02$ & $1-$ cell \\
& & & & & & \\
$\mathrm{A}-\mathrm{Y}$ & $2.00 \mathrm{E}-02$ & $2.14 \mathrm{E}-02$ & $2.19 \mathrm{E}-02$ & $2.29 \mathrm{E}-02$ & $2.44 \mathrm{E}-02$ & $1-$-cell \\
\hline
\end{tabular}

Table 2. Capacitances of $C_{X Y}$ and $C_{A Y}$ per unit cell

shows the firing and sustain voltages with variations of the address electrode width. The firing voltage was measured at the driving frequency of $20 \mathrm{kHz}$ with a duty ratio of $30 \%$. The maximum firing voltage, $\mathrm{V}_{\text {fmax }}$ is defined as the voltage that turns on the entire cells, where the $V_{\operatorname{fmax}(\mathrm{X}-\mathrm{Y})}$ means the maximum firing voltage between the $\mathrm{X}-\mathrm{Y}$ electrodes, and the $\mathrm{V}_{\text {fmax(A-Y) }}$ means the maximum firing voltage between the A-Y electrodes. The minimum sustain voltage, $\mathrm{V}_{\mathrm{smin}}$ is defined as the voltage that turns off the single cell as the driving voltage decreases from the $V_{\text {fmax }}$ where the $V_{s \min (X-Y)}$ and $V_{\operatorname{smin}(A-Y)}$ mean the minimum sustain voltage between the $\mathrm{X}-\mathrm{Y}$ and $\mathrm{A}-\mathrm{Y}$ electrodes, respectively. As shown in Fig. 3, with an increase in the address electrode width, the firing and sustain voltages between the A-Y electrodes decrease, whereas the firing and sustain voltages between the $\mathrm{X}-\mathrm{Y}$ electrodes increase. The changes in the firing voltage and the sustain voltage between the A-Y electrodes and between X-Y electrodes shows the tendency contrary to the changes of the $C_{A Y}$ and $\mathrm{C}_{\mathrm{XY}}$ caused by the variation in the address electrode width. In particular, the increase in the address electrode width causes a decrease in the capacitance, $\mathrm{C}_{\mathrm{XY}}$, thereby resulting in the slight increase in the firing and sustains voltages between the $\mathrm{X}-\mathrm{Y}$ electrodes. Fig. 4 shows the address and sustain discharge delay times relative to the address electrode width. The address and sustain discharge delay times are measured from the infrared 


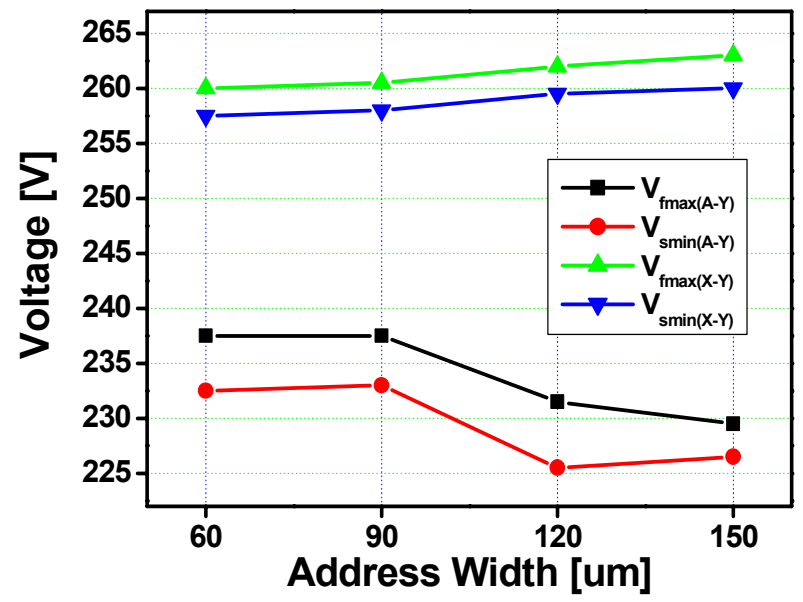

Fig. 3. Firing and sustain voltages between $X-Y$ electrodes and A-Y electrodes

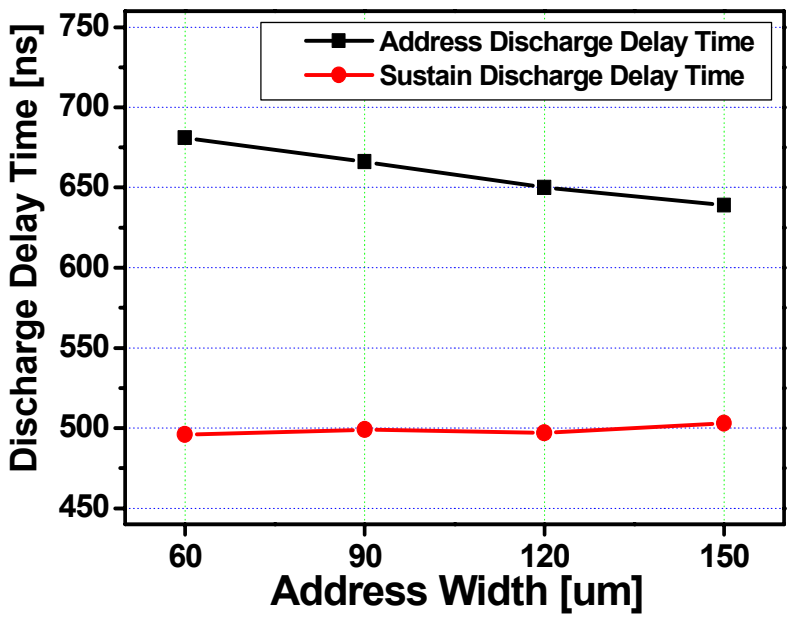

Fig. 4. Address and sustain discharge delay times

emission, which is detected by the photo sensor amplifier (Hamamatsu C6386) in the same subfield. The address or sustain discharge delay time is defined as a time-period from the time when the scan pulse voltage falls to half of its maximum to the time when the emission signal reaches the ninety percent of the peak, which is measured by using an oscilloscope. As shown in Fig. 4, with an increase in the address electrode width, the address discharge delay time decreases, but the sustain discharge delay time increases very slightly. The change in the sustain discharge delay is very small because the sustain pulse has a fast rising and falling time and higher voltage than those of the scan pulse. Whereas, the address discharge delay times can be reduced by about $35 \mathrm{~ns}$ as a result of the capacitance variation, $\Delta \mathrm{C}_{\mathrm{AY}}=0.0044$ $\mathrm{pF}$.

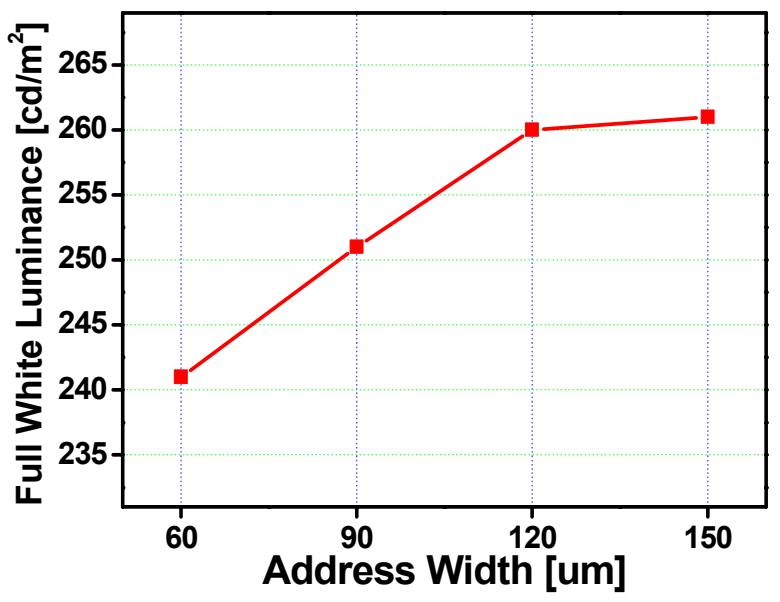

Fig. 5. Full white luminance with the width of an address electrode

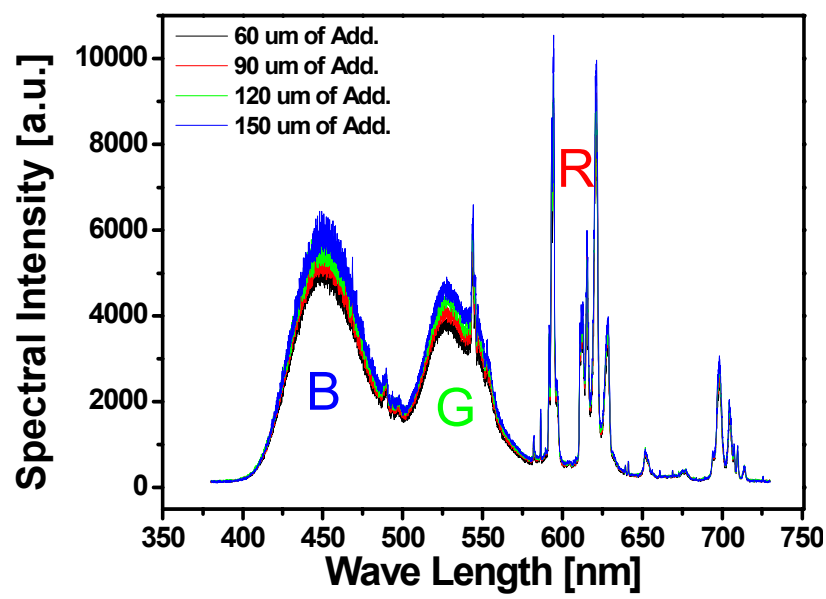

Fig. 6. Spectral intensity of visible with the width of an address electrode

Fig. 5 shows the changes in the full-white luminance relative to the address electrode width. As shown in Fig. 5, the full-white luminance tends to increase with an increase in the address electrode width. This result implies that the variation in the address electrode width affects the sustain discharge characteristics, especially luminance. That is to say, the surface discharge produced between the two coplanar electrodes is affected by the grounded address electrode. It is found that as the address electrode width increases, the electric field in the vicinity of the address electrode is intensified according the simulation result (not shown here) of spatial distribution of electric field. The visible spectral intensity ranging from 370 to $730 \mathrm{~nm}$ is measured with address electrode width and its result is shown in Fig. 6. As shown in Fig. 6, all spectral intensities of R, G and B are increased as the address electrode width becomes broaden. 


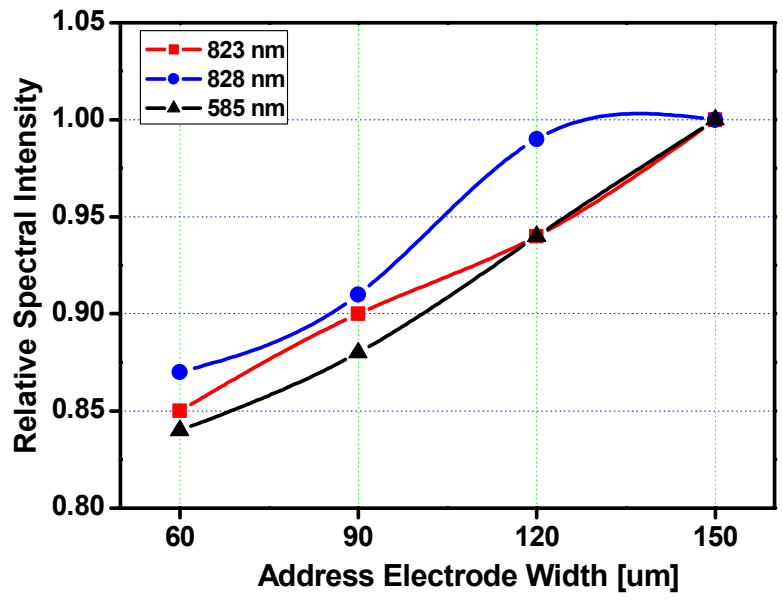

Fig. 7. Relative spectral intensities $(828,823$ and $585 \mathrm{~nm})$ with the width of an address electrode

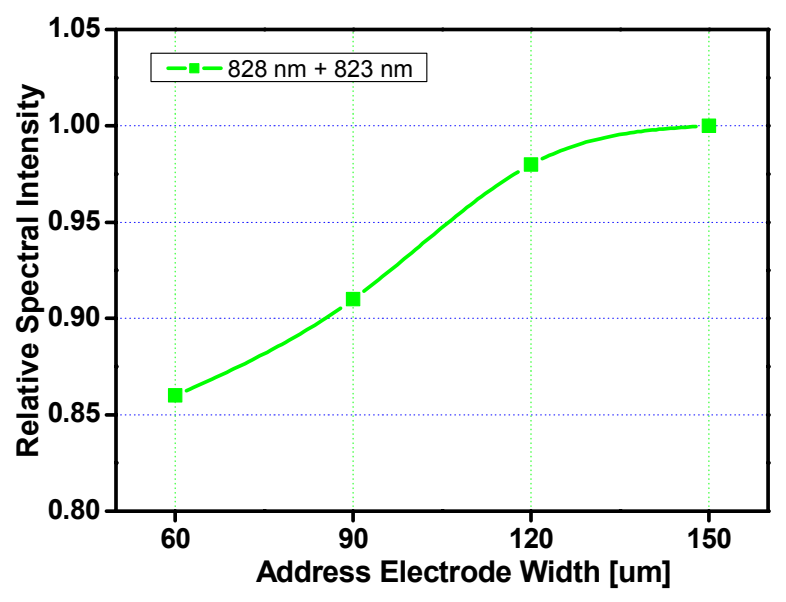

Fig. 8. Relative spectral intensity ( 828 adds to $823 \mathrm{~nm})$ with the width of an address electrode

The spectral intensities of IR rays ( 828 and $823 \mathrm{~nm})$ and neon ray $(585 \mathrm{~nm})$ are measured with the address electrode width, and its result is shown in Figs. 7 and 8. In Figs. 7 and 8, the respective spectral intensity is normalized in such a manner that the value of the spectral intensity is 1 at the address electrode width of $150 \mu \mathrm{m}$. As shown in Fig. 7, the spectral intensities of not only IR rays but also neon ray increase with an increase of the address electrode width. The increase in the address electrode causes the intensification of electric field in the vicinity of the address electrode, thereby resulting in an increase in the IR (828 and 823 $\mathrm{nm})$ plus $\mathrm{Ne}$ emission. As shown in Figs. 5 and 8, when the address electrode width increases, the tendency of the full-white luminance is very similar to that of IR emission. The luminance increase in Fig. 5 strongly depends on the change in the sustain discharge characteristics such as VUV emissions induced by the variation in the address electrode width.

\section{Summary}

The variation of the capacitances among the electrodes and the discharge characteristics with an increase the address electrode width were investigated in the 50-inch ac-PDP. As the width of an address electrode is wider, the capacitance between the sustain and address electrodes $\left(\mathrm{C}_{\mathrm{AY}}\right)$ increases but the capacitance between the two sustain electrodes $\left(\mathrm{C}_{\mathrm{XY}}\right)$ decreases. The changes in the sustain and address discharge characteristics, such as a firing voltage, sustain voltage, discharge delay time and full white luminance are also examined. The increase in the address electrode width causes the increase in the firing voltage between the sustain electrodes, which is due to the decrease in the capacitance between two sustain electrodes, and also causes an increase in the sustain voltage between the sustain electrodes, which is due to the increase in the wall charges accumulation toward the address electrode. The full white luminance tends to increase with an increase in the address electrode width. It is to say that the surface discharge produced between the two coplanar electrodes is affected by the area of the grounded address electrode.

\section{References}

[1] H. S. Jeong, Y. Murakami, M. Seki and H. Murakami, "Discharge characteristics with respect to width of address electrode using three-dimensional analysis", IEEE Trans. Plasma Sci., vol.29, no.3, pp559-565, 2001.

[2] E. Y. Jeong, J. C. Ahn, S. B. Kim, K. J. Suh, E. G. Heo, B. H. Lee, K. S. Lee, S. B. You, J. S. Jung, J. Y. Park, S. B. Song and H. Y. Lee, "The numerical analysis of capacitance between $\mathrm{X}-\mathrm{Y}$ and $\mathrm{A}-\mathrm{Y}$ on cell parameters in alternatingcurrent plasma display panels", proc. IDW'05, 2005. 